\title{
Enhanced monocyte migration to CXCR3 and CCR5 chemokines in COPD
}

\author{
Claudia Costa ${ }^{1}$, Suzanne L. Traves ${ }^{1}$, Susan J. Tudhope ${ }^{1}$, Peter S. Fenwick ${ }^{1}$, \\ Kylie B.R. Belchamber ${ }^{1}$, Richard E.K. Russell ${ }^{2}$, Peter J. Barnes ${ }^{1}$ and \\ Louise E. Donnelly ${ }^{1}$
}

Affiliations: ${ }^{1}$ Airway Disease, National Heart and Lung Institute, Imperial College London, London, UK. ${ }^{2}$ Chest Clinic, King Edward King VII Hospital, Windsor, UK.

Correspondence: Louise E. Donnelly, Airway Disease, National Heart and Lung Institute, Dovehouse Street, London, SW3 6LY, UK. E-mail: l.donnelly@imperial.ac.uk

ABSTRACT Chronic obstructive pulmonary disease (COPD) patients exhibit chronic inflammation, both in the lung parenchyma and the airways, which is characterised by an increased infiltration of macrophages and T-lymphocytes, particularly $\mathrm{CD}^{+}$cells. Both cell types can express chemokine (C-X-C motif) receptor (CXCR) 3 and $\mathrm{C}-\mathrm{C}$ chemokine receptor 5 and the relevant chemokines for these receptors are elevated in COPD. The aim of this study was to compare chemotactic responses of lymphocytes and monocytes of nonsmokers, smokers and COPD patients towards CXCR3 ligands and chemokine (C-C motif) ligand (CCL)5.

Migration of peripheral blood mononuclear cells, monocytes and lymphocytes from nonsmokers, smokers and COPD patients toward CXCR3 chemokines and CCL5 was analysed using chemotaxis assays.

There was increased migration of peripheral blood mononuclear cells from COPD patients towards all chemokines studied when compared with nonsmokers and smokers. Both lymphocytes and monocytes contributed to this enhanced response, which was not explained by increased receptor expression. However, isolated lymphocytes failed to migrate and isolated monocytes from COPD patients lost their enhanced migratory capacity.

Both monocytes and lymphocytes cooperate to enhance migration towards CXCR3 chemokines and CCL5. This may contribute to increased numbers of macrophages and T-cells in the lungs of COPD patients, and inhibition of recruitment using selective antagonists might be a treatment to reduce the inflammatory response in COPD.

@ERSpublications

Peripheral blood mononuclear cells from COPD patients migrate in greater numbers towards CCL5 and CXCR3 chemokines http://ow.ly/X6iQw

This article has supplementary material available from erj.ersjournals.com

Received: Oct 062015 | Accepted after revision: Jan 062016 | First published online: March 102016

Support statement: This study was supported by GlaxoSmithKline, the National Institute for Health Research Respiratory Disease Biomedical Research Unit at the Royal Brompton and Harefield National Health Service Foundation Trust and Imperial College London. Funding information for this article has been deposited with FundRef.

Conflict of interest: Disclosures can be found alongside the online version of this article at erj.ersjournals.com

Copyright @ERS 2016 


\section{Introduction}

Chronic obstructive pulmonary disease (COPD) is characterised by progressive and largely irreversible deterioration of lung function due to small airway fibrosis and alveolar damage as a result of chronic inflammation [1, 2]. Chronic inflammation in the lung parenchyma and the airways is characterised by increased infiltration of macrophages and T-lymphocytes [3,4]. Although there are increased numbers of $\mathrm{CD}^{+}$and $\mathrm{CD}^{+}$lymphocytes, it is $\mathrm{CD}^{+}$cells that predominate in COPD $[5,6]$. Moreover, the $\mathrm{CD} 8^{+} \mathrm{T}$-cell numbers within the lung parenchyma correlate with airflow limitation, suggesting their importance in COPD pathogenesis [4, 7]. Macrophage numbers are increased in bronchoalveolar lavage (BAL) fluid [8, 9] and sputum [10] of smokers with COPD when compared with nonsmokers, suggesting that enhanced macrophage numbers in COPD lungs are a consequence of increased recruitment of monocytes from the circulation [11], since there is little proliferation within the lung [12]. Once in the lung, monocytes differentiate into macrophages and may then orchestrate many of the pathophysiological features of COPD [9].

The precise role of lymphocytes in the pathophysiology of COPD is uncertain. Classically, immune responses to specific antigenic stimuli are regulated by the pattern of cytokines released by activated T-cells. Type-1 immune responses are associated with lung inflammation in COPD [13, 14], in contrast to that in asthma, which has a type- 2 immune response. The chemokine receptors expressed by type-1 T-cells differ from those expressed by type- 2 cells [15]. Interferon (IFN)- $\gamma$ producing type-1 T-cells most commonly express chemokine (C-X-C motif) receptor (CXCR) 3 and $\mathrm{C}-\mathrm{C}$ chemokine receptor (CCR) 5 $[16,17]$. $\mathrm{CD}^{+}$lymphocytes in lung tissue express CCR5 and CXCR3 and are correlated with disease severity in COPD [18]. However, these receptors are not restricted to T-lymphocytes. CXCR3 are also expressed by B-cells, monocytes, macrophages and airway epithelial cells [19,20], whereas CCR5 are expressed predominantly on monocytes and macrophages [19, 21, 22]. Indeed, CXCR3 are highly expressed on B-cells in lymphoid follicles associated with more severe COPD [23]. Such diverse patterns of chemokine receptor expression indicate that these receptors could alter both innate and adaptive immune responses important in COPD pathogenesis [24].

Three chemokines bind and signal through CXCR3: C-X-C motif ligand (CXCL)9 (also known as monokine induced by IFN- $\gamma$ ), CXCL10 (IFN-inducible protein-10) and CXCL11 (IFN-inducible T-cell $\alpha$-chemoattractant) [21]. The ligands for CCR5 include (C-C motif) ligand (CCL)5 (RANTES), CCL3 (macrophage inflammatory protein (MIP)-1 $\alpha$ ) and CCL4 (MIP-1 $\beta$ ). The expression of CXCR3 and CCR5 on monocytes and T-cells suggests that they may drive recruitment of these cells to inflammatory sites. Moreover, increased concentrations of CXCR3 chemokines and CCL5 in induced sputum of COPD patients [25] further supports a role for CXCR3 and CCR5 in leukocyte recruitment in COPD. The aim of this study was to examine the contribution of CXCR3 and CCR5 to chemotactic responses of lymphocytes and monocytes of nonsmokers, smokers and COPD patients.

\section{Methods}

\section{Subject selection}

The project was approved by the ethics committees of the Royal Brompton and Harefield Hospitals and East Berkshire National Health Service Trust. Diagnosis of COPD was made using Global Initiative for Chronic Obstructive Lung Disease criteria [26]. Inclusion criteria for COPD included smoking history of $\geqslant 10$ pack-years, no history of allergic disease and no history of upper respiratory tract infection the preceding 6 weeks. The inclusion criteria for smokers were similar to COPD, but they were required to have a recent lung function test with normal values. Nonsmoker subjects fulfilled the same inclusion criteria as smokers, but without smoking history. All subjects gave written informed consent.

\section{Chemokine receptor expression in leukocytes from whole blood}

Leukocytes in whole blood were analysed for the expression of CXCR3 and CCR5 using methods described previously [11]. The data are expressed as the percentage of cells expressing the receptor being evaluated and as relative fluorescence, which was calculated using the fluorescence values (mean channel) of the cells stained with phycoerythrin (PE)-conjugated anti-CXCR3 and anti-CCR5 antibodies (R\&D Systems Europe, Abingdon, UK) divided by the fluorescence values (mean channel) for the PE-conjugated IgG2a isotype control.

\section{Isolation of peripheral blood mononuclear cells}

Peripheral blood mononuclear cells (PBMCs) were separated from $60 \mathrm{~mL}$ venous blood as described previously [11].

\section{Isolation of monocyte and non-monocytic cells}

Isolation of monocytes was performed using negative selection with a MACS monocyte isolation kit and magnetic depletion column following the manufacturer's instructions (Miltenyi Biotec, Bisley, UK). 
Non-monocytic cells were obtained by washing the column with isolation buffer (PBS supplemented with $0.5 \%(\mathrm{w} / \mathrm{v})$ bovine serum albumin (BSA) and $0.4 \%(\mathrm{w} / \mathrm{v})$ EDTA) in the absence of the magnet. Both monocytes and non-monocytic cells were resuspended at $3 \times 10^{6}$ cells $\cdot \mathrm{mL}^{-1}$ in RPMI 1640 medium supplemented with $0.5 \%(\mathrm{w} / \mathrm{v})$ BSA.

\section{Measurement of chemotaxis}

Chemotaxis was measured in a 48-well microchemotaxis chamber (Neuroprobe Inc., Gaithersburg, MD, USA) by a modification of the methods of WiLkinson [27] and Matsushima et al. [28], as reported previously [11]. Chemoattractant was loaded into the lower compartment of the chemotaxis chamber, and a cellulose nitrate filter $(8 \mu \mathrm{m}$ pore size) was used to separate the two compartments. Cell suspensions $\left(3 \times 10^{6}\right.$ cells $\left.\cdot \mathrm{mL}^{-1}\right)$ were loaded into the upper chamber and incubated at $37^{\circ} \mathrm{C}$ for 90 min to allow the migration of cells through the filter. The filter was removed, cells in the filter fixed with $70 \%(\mathrm{v} / \mathrm{v})$ ethanol, cell nuclei stained with haematoxylin and the filter dehydrated using increasing concentrations of ethanol. The filters were left in xylene overnight, and then mounted onto glass slides using DePex mounting medium. The leading front method of counting [27] was used, with six high-power fields counted for each data point.

Alternatively, chemotaxis was measured using $8 \mu \mathrm{m}$ pore size transwell filters (Becton-Dickinson, Oxford, $\mathrm{UK}) .150 \mu \mathrm{L}$ of cell suspension $\left(10^{7}\right.$ cells $\left.\cdot \mathrm{mL}^{-1}\right)$ were placed in the transwell insert, and chemoattractant in the well, and incubated at $37^{\circ} \mathrm{C}$ for $1 \mathrm{~h}$ to allow migration of the cells through the filter into the well. Cells were harvested and cell numbers determined using flow cytometry. Cells that had passed through the filter were washed with PBS and resuspended in PBS containing $0.5 \%(\mathrm{w} / \mathrm{v})$ BSA and $0.1 \%(\mathrm{w} / \mathrm{v})$ sodium azide and incubated with $10 \mu \mathrm{L}$ of fluorescein isothiocyanate (FITC)-labelled anti-CD14 antibody, anti-CD3 antibody, anti-CD56 antibody, anti-CD19 antibody or murine IgG1 isotype control antibody for 20 min at $4^{\circ} \mathrm{C}$. Cells were washed and resuspended in $300 \mu \mathrm{L}$ fluorescence-activated cell sorter (FACS) flow containing $0.5 \%(\mathrm{v} / \mathrm{v})$ formaldehyde, and subsequently analysed using forward-scattered light and side-scattered light. Monocytes were identified by $\mathrm{CD} 14^{+}$labelling, lymphocytes as the $\mathrm{CD} 3^{+}$population, natural killer cells as the $\mathrm{CD}^{+} 6^{+}$population and B-cells as the $\mathrm{CD} 19^{+}$population.

\section{Measurement of chemotaxis in the presence of antagonists}

PBMCs were incubated with either of two different CXCR3 antagonists: A (N-(1-(3-(4-ethoxyphenyl)-4oxo-3,4-dihydroquinazolin-2-yl)ethyl)-2-(3-fluoro-4-(trifluoromethyl)phenyl)- $N$-(pyridine-2-ylmethyl)acetamide) and $\mathrm{B}$ (N-(2-(dimethylamino)ethyl)-N-(1-(3-(4ethoxyphenyl)-4-oxo-3,4-dihydroquinoazolin-2-yl)ethyl)-2-(3fluoro-4-(trifluoromethyl)phenyl)acetamide), as described in patent WO02/083143A1 of the T487 series [29] or the CCR5 antagonist: C ( $N$-(tert-butyl)-4-chloro-2-fluoro-5-(4-(3 fluorophenyl)-4-(2(1R,3r,5S)-3-(2-methyl-1Hbenzo[d] imidazole-1-yl)-8-azabicyclo[3.2.1]octan-8-yl)ethyl)piperidine-1-carbonyl) benzenesulfonamide; GlaxoSmithKline, King of Prussia, PA, USA) for $1 \mathrm{~h}$ prior to chemotaxis. Monocytes were migrated towards suspension buffer or chemoattractant.

\section{Statistical analysis}

Statistical analyses were performed using GraphPad Prism (GraphPad Software, San Diego, CA, USA). Group data were expressed as mean \pm SE. Differences between groups were determined using the KruskalWallis test followed by Dunn's comparison. Spearman rank correlation was used to obtain correlation coefficients and differences with $\mathrm{p}<0.05$ were considered statistically significant.

\section{Results}

Subject characteristics

There was no statistical difference between the age of healthy smokers and COPD patients, but COPD patients had smoked significantly more than healthy smokers (table 1). Patients with COPD had significantly worse lung function than smokers or nonsmokers, as indicated by lower values for $\mathrm{FEV}_{1} \%$ pred and $\mathrm{FEV}_{1} /$ FVC ratio (table 1).

\section{Flow cytometric analysis of CXCR3 and CCR5 expression on inflammatory cells}

CXCR3 were present on monocytes and $\mathrm{CD}^{+}$T-lymphocytes, CD4 ${ }^{+}$T-lymphocytes and B-cells, with little expression on neutrophils (table 2). CCR5 were present on monocytes, CD8 ${ }^{+}$T-lymphocytes and $\mathrm{CD}^{+}$T-lymphocytes, with little or no expression on the other inflammatory cell types examined (table 2). There were no differences in the levels of CXCR3 expression on any cell types examined between the three subject groups (table 2). Similarly, there were no differences in the numbers of cells expressing each of these receptors between the groups (online supplementary table 1).

For all inflammatory cell types examined the population of cells expressing the receptors was monophasic, with $>95 \%$ of B-cells and $\geqslant 40 \%$ of monocytes, $50 \%$ of $\mathrm{CD}^{+}$T-lymphocytes and $40 \%$ of $\mathrm{CD} 4^{+}$ T-lymphocytes expressing CXCR3 (table 3). Similarly, there was no difference in the expression of CCR5 
TABLE 1 Demographic data of study participants

\begin{tabular}{lccc} 
& Nonsmokers & Smokers & COPD patients \\
\hline Subjects & 11 & 6 & 24 \\
Age years & $34.6 \pm 7.6$ & $54.5 \pm 10.8$ & $63.7 \pm 7.7^{* * *}$ \\
Sex male:female & $5: 6$ & $2: 4$ & $17: 7$ \\
Smoking history pack-years & 0 & $33.3 \pm 22.3$ & $47.1 \pm 14.3^{* * * * *}$ \\
FEV $\%$ pred & $106.5 \pm 8.5$ & $90.2 \pm 10.9$ & $52.5 \pm 16.6^{* * * * *}$ \\
FEV $/$ FVC ratio & $87.9 \pm 6.4$ & $79.6 \pm 5.3$ & $44 \pm 16.6^{* * * * * *}$ \\
\hline
\end{tabular}

Data are presented as $\mathrm{n}$ or mean \pm SD. COPD: chronic obstructive pulmonary disease; $F E V_{1}$ : forced expiratory volume in $1 \mathrm{~s}$; FVC: forced vital capacity. ${ }^{*}$ : $\mathrm{p}<0.05$ COPD patients versus smokers; **: $\mathrm{p}<0.01$ COPD patients versus smokers; ${ }^{* * *}: p<0.001$ COPD patients versus nonsmokers.

on any of the cell types examined between the three subject groups (table 2). Again, expression of receptor was monophasic, with $\sim 30 \%$ of $\mathrm{CD}^{+}$T-lymphocytes expressing CCR5 and $\sim 15-20 \%$ of monocytes and $\mathrm{CD}^{+}$T-lymphocytes expressing CCR5, but $<10 \%$ of neutrophils and B-lymphocytes on cells from all subject groups expressed CCR5 (table 3). Given the lack of differences in receptor expression between the groups there was no correlation between receptor expression and age of subject or smoking pack-years.

\section{Chemotactic responses of PBMCs towards CXCR3 chemokines}

There was no difference in the basal chemotactic response of PBMCs from nonsmokers, smokers and COPD patients (fig. 1). PBMCs from all subject groups migrated towards CXCR3 chemokines, producing bell-shaped response curves to increasing concentrations of CXCL9, CXCL10 and CXCL11 (fig. 1). Cells from all subject groups migrated towards all three CXCR3 chemokines with no difference in the responsiveness of cells from smokers and nonsmokers. In contrast, PBMCs from COPD patients migrated in greater numbers towards CXCL9 than cells from nonsmokers (fig. 1a), and towards CXCL10 and CXCL11 than cells from smokers and nonsmokers (figs $1 \mathrm{~b}$ and $\mathrm{c}$ ). There were no differences in the median effective concentration (EC50) values of the migratory responses of PBMCs from any of the subject groups to CXCL9, CXCL10 or CXCL11 (online supplementary table 2). In addition, the concentration of chemokine that elicited the maximal chemotactic response was not significantly different between any of the groups (online supplementary table 1).

In order to ensure that the enhanced chemotactic responses of PBMCs from COPD patients were being mediated via CXCR3, migration assays were performed in the presence of the CXCR3 antagonists A and B. The migratory response of PBMCs from COPD patients towards CXCL9, CXCL10 and CXCL11 was completely inhibited by increasing concentrations of compound A with EC50 values of $0.34 \pm 0.05 \mathrm{nM}, 0.74$ $\pm 0.44 \mathrm{nM}$ and $1.56 \pm 0.65 \mathrm{nM}$, respectively, with no statistically significant difference in the potency of the antagonist against the three CXCR3 chemokines (fig. 2a-c). Similarly, a second CXCR3 antagonist, compound $\mathrm{B}$, also completely inhibited the migratory response of PBMCs from COPD patients towards CXCL9, CXCL10 and CXCL11 with EC50 values of $0.35 \pm 0.20 \mathrm{nM}, 0.58 \pm 0.21 \mathrm{nM}$ and $0.44 \pm 0.11 \mathrm{nM}$, respectively, with no differences in the potency of the antagonist against the three CXCR3 chemokines (fig. $2 \mathrm{~d}-\mathrm{e}$ ).

TABLE 2 Relative expression (mean fluorescence intensity) of chemokine (C-X-C motif) receptor (CXCR)3 and $\mathrm{C}-\mathrm{C}$ chemokine receptor (CCR)5 on circulating leukocytes of nonsmokers, smokers and patients with chronic obstructive pulmonary disease (COPD)

\begin{tabular}{|c|c|c|c|c|c|c|}
\hline & \multicolumn{2}{|c|}{ Nonsmokers } & \multicolumn{2}{|c|}{ Smokers } & \multicolumn{2}{|c|}{ COPD patients } \\
\hline & CXCR3 & CCR5 & CXCR3 & CCR5 & CXCR3 & CCR5 \\
\hline CD14 ${ }^{+}$monocytes & $5 \pm 2$ & $7 \pm 1$ & $7 \pm 3$ & $6 \pm 1$ & $4 \pm 1$ & $7 \pm 1$ \\
\hline $\mathrm{CD}^{16}{ }^{+}$neutrophils & $2 \pm 0.2$ & $1 \pm 0.8$ & $2 \pm 0.2$ & $2 \pm 0.6$ & $2 \pm 0.1$ & $2 \pm 0.9$ \\
\hline $\mathrm{CD8}^{+} \mathrm{T}$-cells & $9 \pm 1$ & $12 \pm 2$ & $12 \pm 1$ & $7 \pm 1$ & $9 \pm 0.4$ & $8 \pm 1$ \\
\hline $\mathrm{CD4}^{+} \mathrm{T}$-cells & $20 \pm 1$ & $9 \pm 2$ & $22 \pm 3$ & $7 \pm 1$ & $18 \pm 2$ & $7 \pm 1$ \\
\hline CD19+ B-cells & $53 \pm 5$ & $1 \pm 0.4$ & $47 \pm 4$ & $2 \pm 0.7$ & $70 \pm 14$ & $1 \pm 0.3$ \\
\hline
\end{tabular}

Data are presented as mean \pm SEM. $n=8-11$. 
TABLE 3 Percentage of circulating leukocytes that express chemokine ( $\mathrm{C}-\mathrm{X}-\mathrm{C}$ motif) receptor (CXCR)3 and $\mathrm{C}-\mathrm{C}$ chemokine receptor (CCR)5

\begin{tabular}{|c|c|c|c|c|c|c|}
\hline & \multicolumn{2}{|c|}{ Nonsmokers } & \multicolumn{2}{|c|}{ Smokers } & \multicolumn{2}{|c|}{ COPD } \\
\hline & CXCR3 & CCR5 & CXCR3 & $\overline{\text { CCR5 }}$ & CXCR3 & CCR5 \\
\hline CD14 ${ }^{+}$monocytes & $43 \pm 7$ & $15 \pm 3$ & $41 \pm 9$ & $12 \pm 4$ & $37 \pm 6$ & $14 \pm 2$ \\
\hline $\mathrm{CD} 16^{+}$neutrophils & $7 \pm 1$ & $5 \pm 2$ & $7 \pm 1$ & $3 \pm 1$ & $6 \pm 1$ & $4 \pm 1$ \\
\hline CD8 ${ }^{+}$T-cells & $50 \pm 6$ & $35 \pm 5$ & $68 \pm 4$ & $27 \pm 3$ & $67 \pm 3$ & $34 \pm 4$ \\
\hline $\mathrm{CD4}^{+} \mathrm{T}$-cells & $44 \pm 3$ & $17 \pm 2$ & $41 \pm 3$ & $14 \pm 2$ & $44 \pm 6$ & $22 \pm 3$ \\
\hline CD19+ B-cells & $>95$ & $5 \pm 0.3$ & $>95$ & $4 \pm 1$ & $>95$ & $5 \pm 1$ \\
\hline
\end{tabular}

Data are presented as mean \pm SEM. $n=8-11$.

\section{Chemotactic responses to CCL5}

In order to determine whether the enhanced migratory response of PBMCs from COPD patients was restricted to CXCR3 chemokines, the effects of a CCR5 ligand, CCL5, was examined. PBMCs from all subject groups migrated towards CCL5, producing a bell-shaped response curve (fig. 3a). Again, PBMCs from COPD patients migrated in greater numbers than cells from nonsmokers and smokers (fig. 3a). As with the CXCR3 chemokines, there was no significant difference in the potency of CCL5 on the migratory responses of PBMCs from any of the subject groups (online supplementary table 1). Similarly, the concentration of CCL5 required for a maximal migratory response was similar for all three subject groups (online supplementary table 1).

CCL5 is promiscuous and will bind a number of receptors including CCR5, CCR1 and CCR3. As CCR1 is expressed on monocytes, the specificity of the enhanced migratory response of PBMCs from COPD patients was assessed using a CCR5-selective antagonist. The migratory response of PBMCs from COPD patients towards CCL5 was completely inhibited by increasing concentrations of antagonist C with an EC50 value of $0.4 \pm 0.07 \mathrm{nM}$ (fig. $3 \mathrm{~b}$ ), suggesting that this migration is preferentially via CCR5, and not through any other chemokine receptors, including CCR1.

\section{Identification of migrating PBMCs}

PBMCs comprise a variety of cell types, including T-lymphocytes, B lymphocytes, natural killer (NK) cells and monocytes. Expression of CXCR3 and CCR5 receptors is not restricted to a single cell type, therefore within the PBMC fraction a number of different cell types may be migrating and this population may be different in COPD patients. In order to determine which cell population was responsible for the enhanced migratory effect observed in PBMCs from COPD patients, an alternative chemotactic assay was applied which enabled identification of the migratory population of cells. Using PBMCs from COPD patients only and a transwell migratory system, T-lymphocytes $\left(\mathrm{CD}^{+}\right)$and $\mathrm{NK}$ cells $\left(\mathrm{CD} 56^{+}\right)$migrated towards both CXCL10 and CCL5, with fewer monocytes $\left(\mathrm{CD} 14^{+}\right)$and B-cells $\left(\mathrm{CD} 19^{+}\right)$migrating (fig. 4).
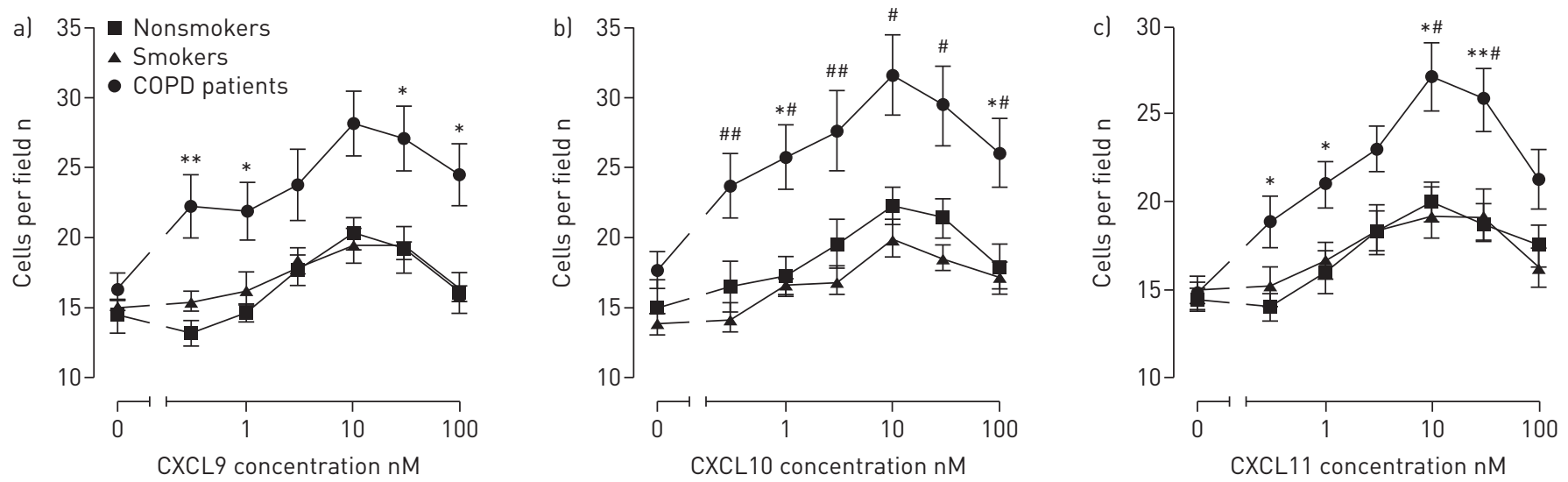

FIGURE 1 Migration of peripheral blood mononuclear cells (PBMCs) from nonsmokers, smokers and chronic obstructive pulmonary disease (COPD) patients towards chemokine ( $C-X-C$ motif) receptor (CXCR)3 chemokines. PBMCs were isolated from nonsmokers ( $n=6$ ), smokers ( $=6$ ) and COPD patients $(n=10)$ and chemotaxis experiments performed towards a) chemokine (C-X-C motif) ligand (CXCL)9, b) CXCL10 or c) CXCL11. The number of cells present in the filter from $20 \mu \mathrm{m}$ onward was counted. Data are presented as mean \pm SEM. ${ }^{*}: \mathrm{p}<0.05$ and ${ }^{* *}$ : $p<0.01$ for COPD patients versus nonsmokers; ${ }^{\#}$ : $p<0.05$ and ${ }^{\# \#}$ : $p<0.01$ for COPD patients versus smokers. 

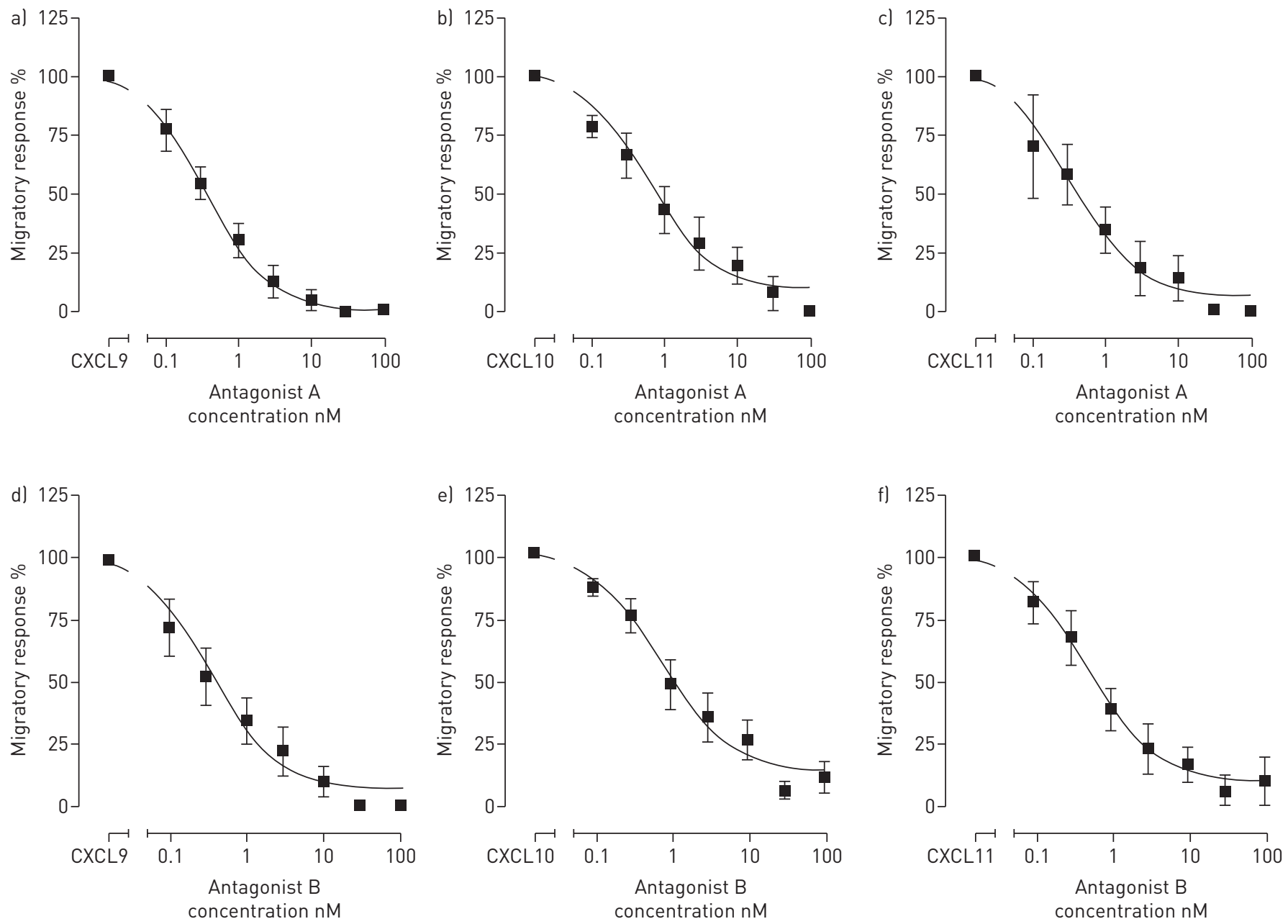

FIGURE 2 Effect of chemokine ( $C-X-C$ motif) receptor (CXCR)3 antagonists on the migratory responses of peripheral blood mononuclear cells (PBMCs) from chronic obstructive pulmonary disease (COPD) patients. PBMCs were isolated from COPD patients and pre-incubated for $1 \mathrm{~h}$ with either $\mathrm{a}-\mathrm{C}$ ) antagonist $\mathrm{A}$; or $\mathrm{d}-\mathrm{f}$ ) antagonist $\mathrm{B}$ prior to chemotaxis towards $7.5 \mathrm{nM}$ a, d) chemokine (C-X-C motif) ligand (CXCL)9; b, e) CXCL10; or c, f) CXCL11. The number of cells present in the filter from $20 \mu \mathrm{m}$ onward was counted. Data are presented as mean \pm SEM. $\mathrm{n}=6$. A: N-(1-(3-(4-ethoxyphenyl)-4-oxo-3,4-dihydroquinazolin-2-yl)ethyl)-2-3-fluoro-4-(trifluoromethyl)phenyl)-N-(pyridine-2-ylmethyl)acetamide; B: N-(2(dimethylamino)ethyl)-N-1-(3-(4ethoxyphenyl)-4-oxo-3,4-dihydroquinoazolin-2-yl)ethyl)-2-3-(3-fluoro-4-(trifluoromethyl)phenyl)acetamide.

In order to establish which cell type was responsible for the enhanced migratory response of PBMCs towards CXCR3 chemokines and CCL5 the monocytes were specifically selected from the other cells in the PBMC fraction and both the monocyte fraction and the remainder of the cells (lymphocytes) were migrated towards a single, submaximal concentration $(7.5 \mathrm{nM})$ of chemokine. Cells from COPD patients and nonsmokers were used for these experiments as there were no differences in the responses of cells from smokers and nonsmokers. In both cases, isolated monocytes migrated towards the CXCR3 chemokines, but there was little migration observed in the lymphocyte population over the buffer control (fig. 5). In addition, the enhanced migratory response of cells from COPD patients was lost when the cells were isolated, since monocytes from COPD patients migrated in the same numbers as those from nonsmokers (fig. 5). A similar effect was seen in the responsiveness of isolated cells to CCL5 (data not shown).

\section{Discussion}

Chemotaxis of inflammatory cells is part of the normal immune response to various stimuli [30]. However, the increased number of macrophages and T-lymphocytes in the parenchyma and airways of patients with COPD suggests increased cell trafficking from the circulation to the lungs [11]. The present study compared the migration of PBMCs from nonsmokers, smokers and COPD patients toward CCL5 and the CXCR3 chemokines in an attempt to examine the mechanisms of this increased inflammatory infiltrate in COPD.

PBMCs from nonsmokers, smokers and COPD patients migrated towards CXCL9, CXCL10, CXCL11 and CCL5 with similar responses of cells from smokers and nonsmokers. In contrast, the migratory responses 

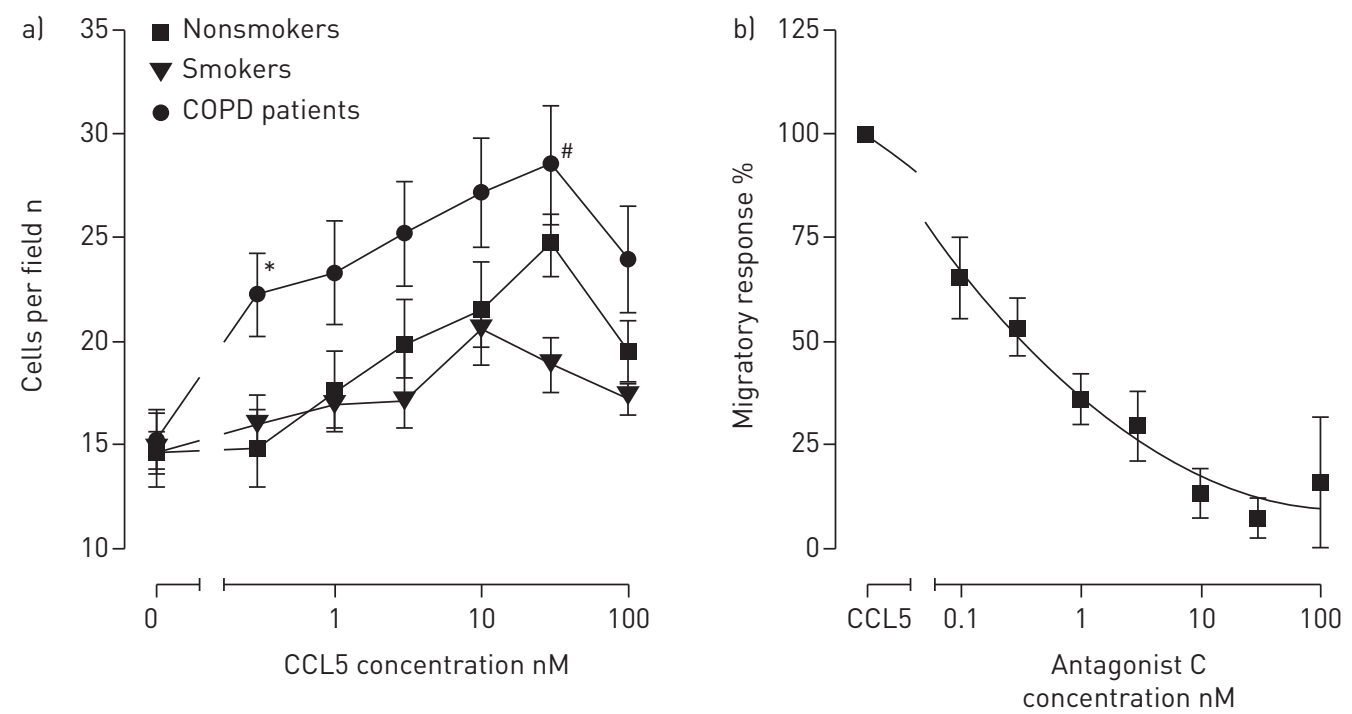

FIGURE 3 Migration response of peripheral blood mononuclear cells (PBMCs) towards chemokine (C-C motif) ligand (CCL)5. PBMCs were isolated from nonsmokers $(n=6)$, smokers $(n=6)$ and chronic obstructive pulmonary disease (COPD) patients $(n=10)$. a) Chemotaxis experiments towards $C C L 5$; b) the effect of the $C-C$ motif receptor 5 antagonist GSK222474A (antagonist C) on PBMCs from COPD patients. The PBMCs were pre-incubated for $1 \mathrm{~h}$ with the antagonist prior to chemotaxis towards $7.5 \mathrm{nM} \mathrm{CCL5}$. The number of cells present in the filter from $20 \mu \mathrm{m}$ onward was counted. Data are presented as mean \pm SEM. * : p<0.05 for COPD versus nonsmokers; " : $<0.05$ for COPD versus smokers.

of cells from COPD patients were heightened compared with control groups for all chemokines studied. There was no difference between the potency of the chemokines studied between the groups analysed, but the efficacy of chemokines was greater in patients with COPD, with more cells migrating to a given chemokine. As the age of the patients with COPD patients matched that of the smokers, it is unlikely that this is a confounding factor in this study since there were no correlations with chemokine efficacy and age in the COPD group (data not shown). Receptor antagonists confirmed the involvement of CXCR3 and CCR5 in these responses.

Differences in the chemotactic responses between PBMCs from COPD patients and nonsmokers were observed, even at the lowest concentration of chemokines studied $(0.3 \mathrm{nM})$, suggesting that at low concentrations of chemokines, cells from COPD patients are activated and migrate in greater numbers. This enhanced migratory response is unlikely to be due to increased receptor numbers on the surface of cells derived from COPD patients as we were unable to detect any differences in cell surface expression of either CXCR3 or CCR5 on any inflammatory cell in whole blood using flow cytometric analysis.

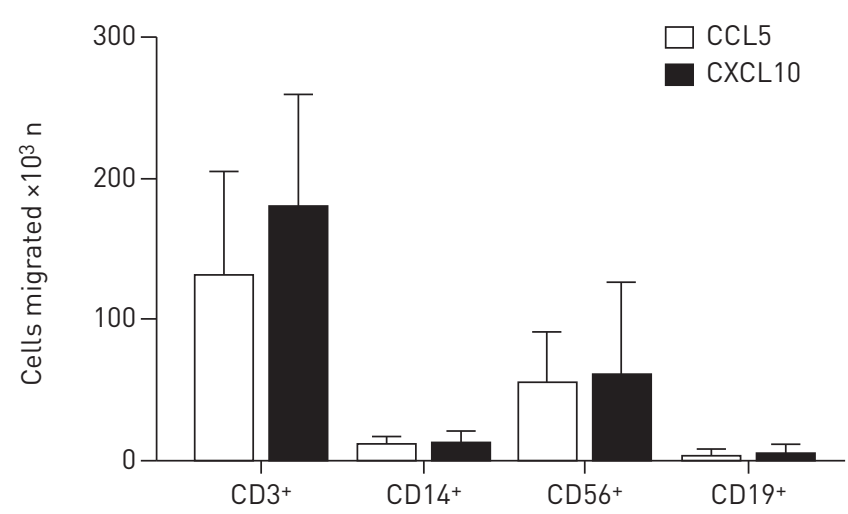

FIGURE 4 Identification of migrated chronic obstructive pulmonary disease (COPD) cell types. Peripheral blood mononuclear cells (PBMCs) from COPD patients were allowed to migrate through an $8 \mu \mathrm{m}$ pore-size transwell towards $100 \mathrm{nM}$ chemokine (C-X-C motif) ligand (CXCL)10 or (C-C motif) ligand (CCL)5 for $1 \mathrm{~h}$. Cells collected in the well were identified using positive staining for CD3, CD14, CD56 or CD19 using flow cytometric analysis. Data are presented as mean \pm SEM of the number of cells migrated after subtraction of background migration to buffer alone. $n=6$. 

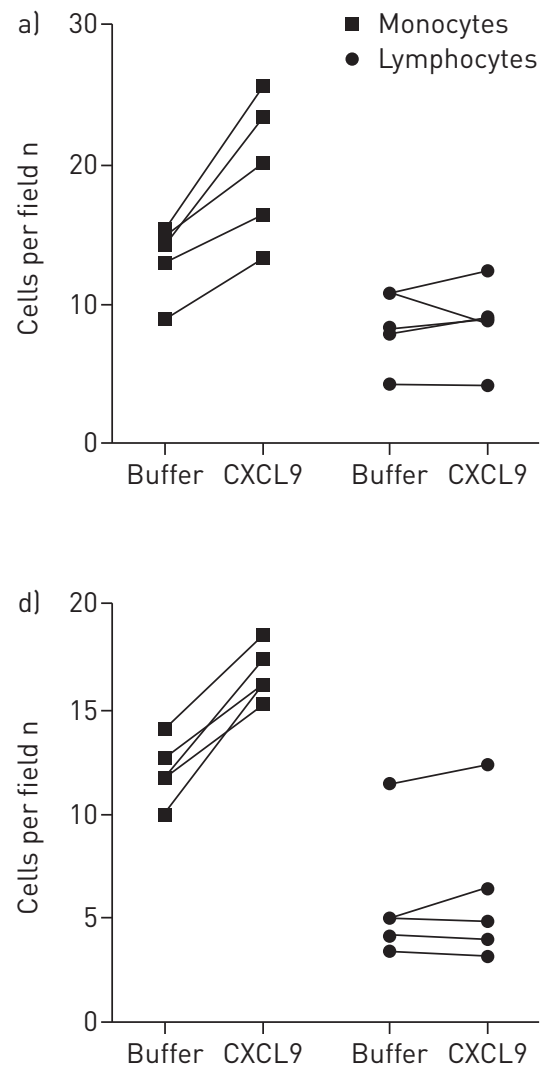
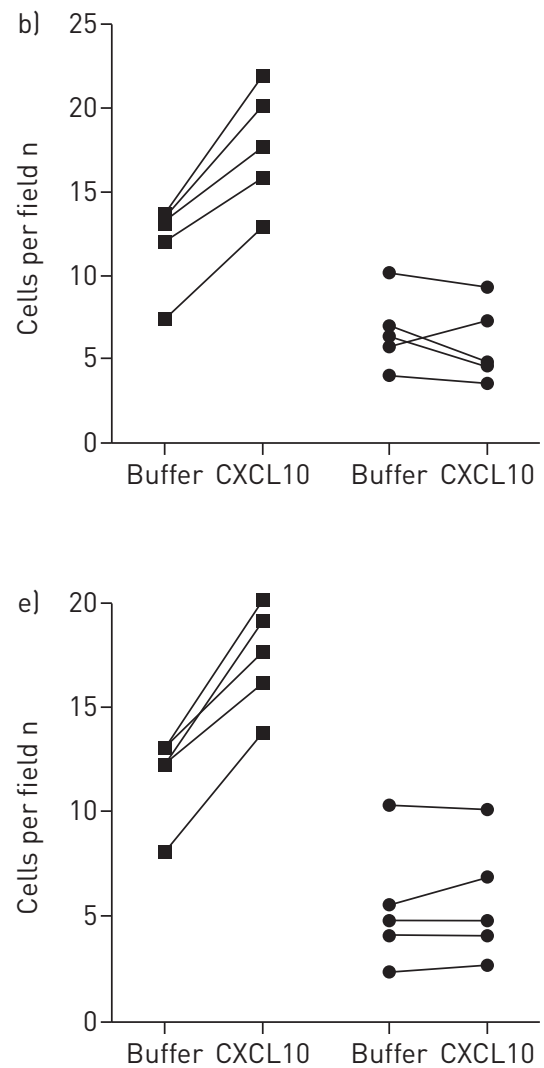
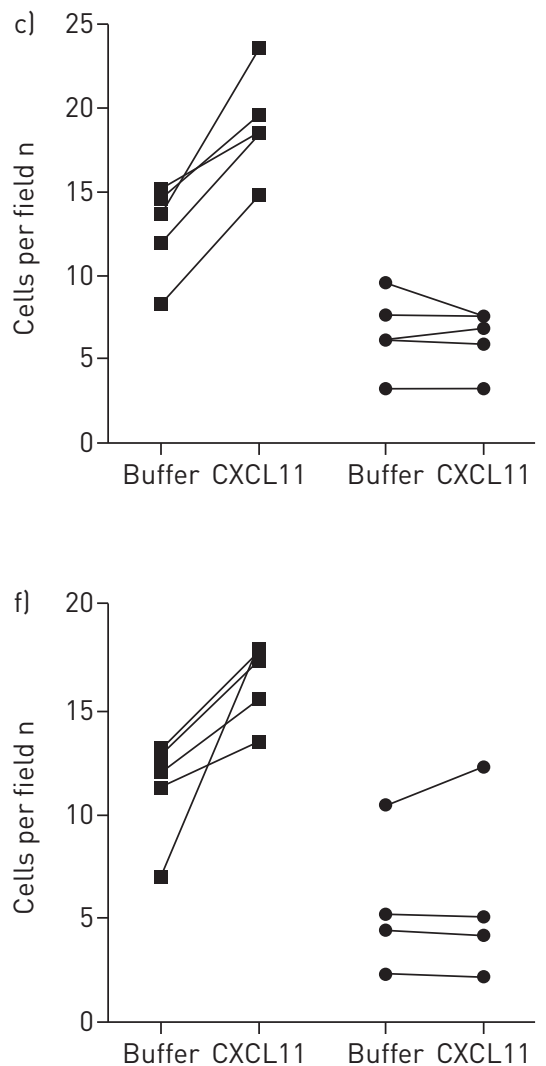

FIGURE 5 Effect of separating monocytes and lymphocytes from chronic obstructive pulmonary disease (COPD) patients and nonsmokers on migratory responses towards $\mathrm{C}$ chemokine ( $\mathrm{C}-\mathrm{X}-\mathrm{C}$ motif) receptor (CXCR)3 ligands. Monocytes and lymphocytes were further isolated from the peripheral blood mononuclear cells of $a-c$ ) nonsmokers and $d-f$ ) COPD patients and chemotaxis performed towards a, d) chemokine (C-X-C motif) ligand (CXCL)9; b, e) CXCL10; and C, f) CXCL11 or suspension buffer control. The number of cells present in the filter from $20 \mu \mathrm{m}$ onward was counted. The migration of cells from each individual subject is shown.

The heightened chemotactic response of PBMCs from COPD patients toward CXCR3 chemokines and CCL5 is a novel finding that is likely to be important in the pathophysiology of COPD. Moreover, this increased response involves lymphocyte, NK cell and monocyte components. We have previously demonstrated that PBMCs and monocytes from patients with COPD will migrate in increased numbers to some but not all CXCR2 agonists by a mechanism that involves downregulation and increased cycling of cell surface receptors [11]. In contrast, all CXCR3 agonists and CCL5 elicited similar responses. Although both lymphocytes and monocytes isolated from peripheral blood express CXCR3 and CCR5, the relative expression of these receptors was not altered in COPD. Grumelli et al. [22] also reported highly variable expression of CXCR3 and CCR5 on lymphocytes isolated from peripheral blood similar to that presented here, but this contrasts with of $\mathrm{KoCH}$ et al. [31], who described increased expression of CXCR3 on CD8 ${ }^{+}$ cells in COPD and BROZYNA et al. [32], who also showed increased expression of CXCR3 and CCR5 in T-helper type 1 cells. Increased expression of CXCR3 and CCR5 has also been reported on lung lymphocytes and macrophages from patients with COPD [22]. However, it is unclear if circulating lymphocytes from patients with COPD are activated, although circulating lymphocytes in emphysema patients do not show any difference in activation markers compared with control subjects [33]. However, the present study did not discriminate between patients with chronic bronchitis and emphysema so differences in activation markers were not assessed directly in the present study.

Our study shows that PBMCs and isolated monocytes migrate toward all of the chemokines we investigated, whereas isolated lymphocytes did not respond to these same chemokines. This concurs with a previous report that only activated lymphocytes migrate towards CXCL11 [34]. One possibility for the data in the present study is that lymphocytes in PBMCs from patients with COPD are stimulated by the presence of other leukocytes in the PBMC fraction, as they could migrate in the transwell assays.

This study indicates that PBMCs and monocytes from all three groups of subjects migrate toward CXCR3 chemokines and CCL5. However, in COPD, PBMCs and monocytes can be recruited in higher numbers to the chemokines studied and contribute to the accumulation of macrophages and lymphocytes in lung 
parenchyma and airways. Neutralisation of CXCR3 and CCR5 receptors from COPD patients with receptor antagonists could therefore offer a therapeutic option for reducing the inflammatory infiltrate observed. While CXCR3 antagonists are in preclinical development, CCR5 antagonists have been developed for HIV/AIDS and one such drug, maraviroc, is currently approved for clinical use [35]. Therefore, it may be possible to test CCR5 antagonists in clinical studies in COPD patients in the near future. A limitation of our study is the small numbers of subjects, particularly in the control groups; however, the observation that cooperativity occurs between different leukocyte populations with respect to cell migration was observed in all subjects.

In summary, PBMCs from COPD patients migrate in greater numbers towards CCL5 and CXCR3 chemokines. Although the lymphocytes contribute to this response, this is lost when the cells are isolated, suggesting cross-talk between circulating lymphocytes and monocytes in COPD patients that promotes increased migration into the lung leading to the chronic inflammation.

\section{References}

1 Wouters EF. Local and systemic inflammation in chronic obstructive pulmonary disease. Proc Am Thorac Soc 2005; 2: 26-33.

2 Barnes PJ. Cellular and molecular mechanisms of chronic obstructive pulmonary disease. Clin Chest Med 2014; 35: 71-86.

3 Lams BE, Sousa AR, Rees PJ, et al. Immunopathology of the small-airway submucosa in smokers with and without chronic obstructive pulmonary disease. Am J Respir Crit Care Med 1998; 158: 1518-1523.

4 O'Shaughnessy TC, Ansari TW, Barnes NC, et al. Inflammation in bronchial biopsies of subjects with chronic bronchitis: inverse relationship of $\mathrm{CD}^{+} \mathrm{T}$ lymphocytes with FEV1. Am J Respir Crit Care Med 1997; 155: 852-857.

5 Jeffery PK. Comparison of the structural and inflammatory features of COPD and asthma. Giles F. Filley Lecture. Chest 2000; 117: Suppl. 1, 251S-260S.

6 Saetta M, Baraldo S, Corbino L, et al. CD8+ve cells in the lungs of smokers with chronic obstructive pulmonary disease. Am J Respir Crit Care Med 1999; 160: 711-717.

7 Di Stefano A, Capelli A, Lusuardi M, et al. Severity of airflow limitation is associated with severity of airway inflammation in smokers. Am J Respir Crit Care Med 1998; 158: 1277-1285.

8 Barnes PJ. Chronic obstructive pulmonary disease. N Engl J Med 2000; 343: 269-280.

9 Barnes PJ. Alveolar macrophages as orchestrators of COPD. COPD 2004; 1: 50-70.

10 Keatings VM, Barnes PJ. Granulocyte activation markers in induced sputum: comparison between chronic obstructive pulmonary disease, asthma, and normal subjects. Am J Respir Crit Care Med 1997; 155: 449-453.

11 Traves SL, Smith SJ, Barnes PJ, et al. Specific CXC but not CC chemokines cause elevated monocyte migration in COPD: a role for $\mathrm{CXCR}_{2}$. J Leukoc Biol 2004; 76: 441-450.

12 Tomita K, Caramori G, Lim S, et al. Increased p21(CIP1/WAF1) and B cell lymphoma leukemia-x(L) expression and reduced apoptosis in alveolar macrophages from smokers. Am J Respir Crit Care Med 2002; 166: 724-731.

13 Panina-Bordignon P, D'Ambrosio D. Chemokines and their receptors in asthma and chronic obstructive pulmonary disease. Curr Opin Pulm Med 2003; 9: 104-110.

14 Tzanakis $\mathrm{N}$, Chrysofakis $\mathrm{G}$, Tsoumakidou $\mathrm{M}$, et al. Induced sputum $\mathrm{CD} 8^{+} \mathrm{T}$-lymphocyte subpopulations in chronic obstructive pulmonary disease. Respir Med 2004; 98: 57-65.

15 Campbell DJ, Debes GF, Johnston B, et al. Targeting T cell responses by selective chemokine receptor expression. Semin Immunol 2003; 15: 277-286.

16 Sallusto F, Kremmer E, Palermo B, et al. Switch in chemokine receptor expression upon TCR stimulation reveals novel homing potential for recently activated T cells. Eur J Immunol 1999; 29: 2037-2045.

17 Annunziato F, Cosmi L, Galli G, et al. Assessment of chemokine receptor expression by human Th1 and Th2 cells in vitro and in vivo. J Leukoc Biol 1999; 65: 691-699.

18 Freeman CM, Curtis JL, Chensue SW. CC chemokine receptor 5 and CXC chemokine receptor 6 expression by lung $\mathrm{CD}^{+}$cells correlates with chronic obstructive pulmonary disease severity. Am J Pathol 2007; 171: 767-776.

19 Murphy PM, Baggiolini M, Charo IF, et al. International union of pharmacology. XXII. Nomenclature for chemokine receptors. Pharmacol Rev 2000; 52: 145-176.

20 Kelsen SG, Mardini IA, Zhou S, et al. A technique to harvest viable tracheobronchial epithelial cells from living human donors. Am J Respir Cell Mol Biol 1992; 7: 66-72.

21 Petkovic V, Moghini C, Paoletti S, et al. I-TAC/CXCL11 is a natural antagonist for CCR5. J Leukoc Biol 2004; 76: 701-708

22 Grumelli S, Corry DB, Song LZ, et al. An immune basis for lung parenchymal destruction in chronic obstructive pulmonary disease and emphysema. PLoS Med 2004; 1: e8.

23 Kelsen SG, Aksoy MO, Georgy M, et al. Lymphoid follicle cells in chronic obstructive pulmonary disease overexpress the chemokine receptor CXCR3. Am J Respir Crit Care Med 2009; 179: 799-805.

24 Curtis JL, Freeman CM, Hogg JC. The immunopathogenesis of chronic obstructive pulmonary disease: insights from recent research. Proc Am Thorac Soc 2007; 4: 512-521.

25 Costa C, Rufino R, Traves SL, et al. CXCR3 and CCR5 chemokines in induced sputum from patients with COPD. Chest 2008; 133: 26-33.

26 Global Initative for Chronic Obstructive Lung Disease. Global Strategy for the Diagnosis, Management and Prevention of COPD. www.goldcopd.org/guidelines-global-strategy-for-diagnosis-management.html Date last accessed: August 10, 2015. Last updated 2014.

27 Wilkinson PC. Micropore filter methods for leukocyte chemotaxis. Methods Enzymol 1988; 162: 38-50.

28 Matsushima K, Larsen CG, DuBois GC, et al. Purification and characterization of a novel monocyte chemotactic and activating factor produced by a human myelomonocytic cell line. J Exp Med 1989; 169: 1485-1490.

29 Medina JC, Tularik Inc., assignee. CXCR3 Antagonists. Patent WO/2002/083143. 2002. 
30 Proudfoot AE. Chemokine receptors: multifaceted therapeutic targets. Nat Rev Immunol 2002; 2: 106-115.

31 Koch A, Gaczkowski M, Sturton G, et al. Modification of surface antigens in blood CD8 ${ }^{+}$T-lymphocytes in COPD: effects of smoking. Eur Respir J 2007; 29: 42-50.

32 Brozyna S, Ahern J, Hodge G, et al. Chemotactic mediators of Th1 T-cell trafficking in smokers and COPD patients. COPD 2009; 6: 4-16.

33 Morissette MC, Parent J, Milot J. Perforin, granzyme B, and FasL expression by peripheral blood T lymphocytes in emphysema. Respir Res 2007; 8: 62.

34 Cole KE, Strick CA, Paradis TJ, et al. Interferon-inducible T cell alpha chemoattractant (I-TAC): a novel non-ELR CXC chemokine with potent activity on activated T cells through selective high affinity binding to CXCR3. J Exp Med 1998; 187: 2009-2021.

35 Fadel H, Temesgen Z. Maraviroc. Drugs Today 2007; 43: 749-758. 